\title{
Humanities
}

\section{The Still Point: A Medical Student's Experience in Using Poetry to Improve Clinical Communication}

I sat across from an in-patient as his attending physician told him about his newly discovered "pancreatic mass". The mass was likely cancerous and had a poor prognosis the physician stated, flatly. The patient watched carefully as the physician spoke; he nodded in apparent understanding. At the end of the encounter the physician asked if the patient had any questions. The patient mumbled "no" and the physician described the next diagnostic procedure that would take place the following morning.

One gift of medical students is time; a second gift is approachability. Later that afternoon the patient we had spoken to earlier sat alone in his room. He approached the door to the ward, saw me, and asked, "Can you come in here for a minute, son?" I looked at the patient; he was jaundiced and still. We shared a brief moment of silence before he looked at me and asked, "Does this mean I have cancer?"

An essential challenge for any third year medical student is to translate a wealth of academic information into practical approaches for use in individual patient encounters. The categorical knowledge accumulated in the first two years of medical school must be brought alive and applied to real patients with real problems. This challenge exists in both pathological and communicative domains.

From a pathological perspective there are many resources in place that aid in the aforementioned knowledge translation. I rely on case-based textbooks, clinical experience - a setting where preceptors often provide feedback about approaches to a variety of medical presentations - and case-based methods of evaluation. I use these experiences to move beyond rote memorization of categorical diseases. I am developing clinical reasoning skills that make my background knowledge of disease pathology applicable to a huge variety of clinical presentations.

Along with many medical students in my generation, I have received explicit communication skills training. Successful application of communication guidelines requires knowledge translation appropriate to each patient encounter. While I receive adequate support to translate my knowledge about disease pathology into approaches for the diagnosis and treatment of individual patients, I find these traditional resources to be lacking when it comes to clinical communication; communication skills are almost never discussed during my clinical training and they are difficult to assess through standardized evaluation.

In the still point that was created by the patient's question above, I initially froze. I thought about guidelines I had read on breaking bad news but I had difficulty translating that knowledge into healing words for the specific patient in front of me. I did tell the patient it was very likely that he had cancer and explained what we would be doing in order to confirm that diagnosis. I again asked if he had any questions. He replied, "no".

I continued to feel that I had a poor understanding of the patient's experience and that the patient did not understand his disease. At the end of the day I had a comprehensive read through the patient's chart and later that evening I wrote the following short poem to reflect on the patient's experience:

For years he lived well, best he knew how Had a family and provided

Tough things built up.

Finances; kids; fights;

Some he dealt with, others were left alone the grip of stress, relaxed, with cigarettes and alcohol. Momentary relief through vice

He had found his life's balance; this was his version of "health".

No reason to question, no cause for concern, He hadn't seen a doc in years

Then he was yellow, no other complaints, 5 days later - better get that checked out Nothing major in his mind; he otherwise felt fine

We see painless jaundice + pancreatic mass on CT; Adenocarcinoma until proven otherwise.

The knowing, certainty, and routine of medicine Meet surprise, denial, and fear. 
I find poetry to be a means of translation. Writing poetry requires at minimum two tasks: to step inside the experience of your subject and to put that subject's experience into words. It is these two skills that are required to translate communication guidelines into healing words applicable to individual patients' experiences. As my career develops I will continue to use poetry as a tool to gain confidence and skills in relating to and communicating with patients.

The following morning I visited the patient early, before his procedure. I listened, shared, and connected; it was poetry happening in front of me.

\section{Thomas Muir}

Class of 2012

Faculty of Medicine

Dalhousie University

This passage is based on a compilation of multiple clinical encounters and does not contain information that would be identifiable to one case in particular.

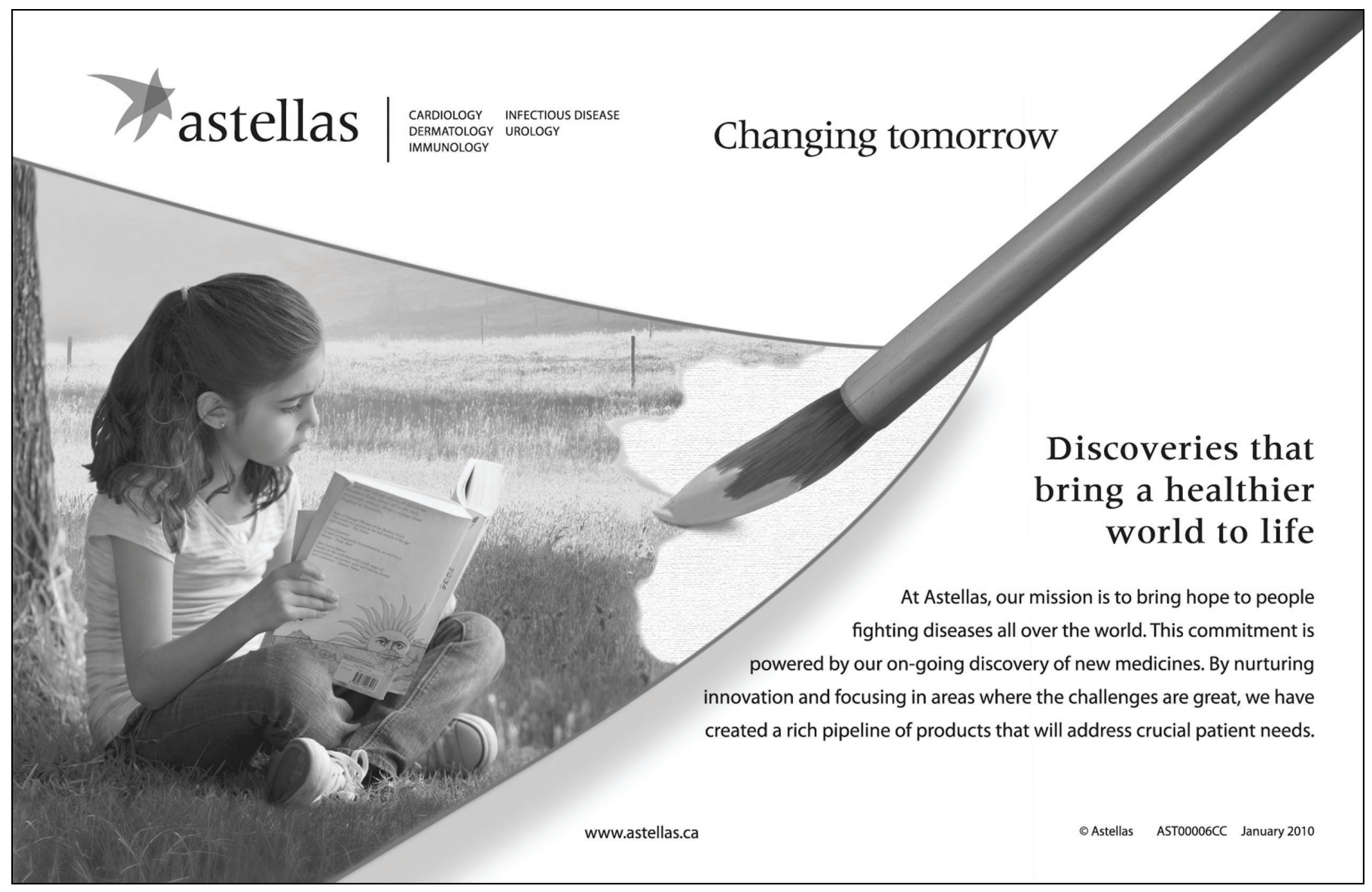

